\title{
Hubungan Konsumsi Makanan Cepat Saji, Tingkat Stres dan Kualitas Tidur terhadap Status Gizi pada Remaja Putra SMA DKI Jakarta
}

\author{
Ismi Aminatyas ${ }^{1}$, Laras Sitoayu ${ }^{{ }^{*}}$, Dudung Angkasa ${ }^{1}$, Nazhif Gifari ${ }^{1}$, \\ Yulia Wahyuni ${ }^{1}$ \\ ${ }^{1}$ Program Studi Ilmu Gizi, Fakultas Ilmu-Ilmu Kesehatan, Universitas Esa Unggul \\ * Alamat korespondensi: laras@esaunggul.ac.id
}

\begin{abstract}
Abstrak
Masalah gizi pada remaja di Indonesia muncul akibat ketidakseimbangan antara konsumsi zat gizi dengan kecukupan gizi yang diperlukan. Tujuan penelitian untuk mengetahui hubungan konsumsi makanan cepat saji, tingkat stres dan kualitas tidur terhadap status gizi pada remaja putra SMA DKI Jakarta. Rancangan penelitian adalah cross-sectional study dengan jumlah responden 160 orang remaja putra. Pengambilan data dilakukan dengan menggunakan kuesioner FFQ, ISMA (International Stress Management Association) dan PSQI (Pittburgh Sleep Quality Index). Analisis data menggunakan uji chi-square. Hasil menunjukkan terdapat hubungan yang signifikan antara tingkat stres terhadap status gizi $(p$-value $=0,017)$. Namun, tidak ada hubungan yang signifikan antara konsumsi makanan cepat saji $(p$-value $=0,210)$ dan kualitas tidur $(p$-value $=0,165)$ terhadap status gizi. Bagi remaja putra diharapkan untuk lebih meningkatkan makanan bergizi seimbang serta memiliki tingkat stres dan kualitas tidur yang baik agar dapat mencapai status gizi normal.

Kata Kunci : Makanan cepat saji, tingkat stres, kualitas tidur, status gizi, remaja putra.
\end{abstract}

\begin{abstract}
Nutrition problems in adolescents in Indonesia arise due to an imbalance between nutritional consumption and the adequacy of nutrients needed. This study aims to find out the relationship between fast-food consumption, stress level, and sleep quality on the nutritional status of male high school adolescents in DKI Jakarta. The study design was cross-sectional. The respondents were 160 male adolescents. Data were collected using FFQ, ISMA (International Stress Management Association), and PSQI (Pittsburgh Sleep Quality Index) questionnaires. Data analysis was done using the chi-square test. The results show a significant relationship between stress level on nutritional status ( $p$-value=0.017). However, there is no significant relationship between consumption of fast food ( $p$-value $=0.210)$ and sleep quality $(p$-value $=0.165)$ on the nutritional status. Male adolescents are expected to increase the nutritionally balanced foods and to have good stress levels and good sleep quality to achieve normal nutritional status.
\end{abstract}

Keywords: Fast food consumption, nutritional status, male adolescent, stress level, sleep quality 


\section{PENDAHULUAN}

Perilaku pengontrolan berat badan yang tidak benar dan kebiasaan makan makanan yang buruk merupakan salah satu contoh ketidakpuasan remaja pada tubuh sendiri yang dapat membahayakan perkembangan pada masa remaja tersebut [1]. Biasanya pada laki-laki akan menunjukan gangguan perilaku makan yang berbeda dari perempuan karena laki-laki ingin memiliki tubuh yang lebih besar untuk massa otot [2].

Pada anak-anak dan remaja usia 5-9 tahun mengalami peningkatan prevalensi pada kelebihan berat badan dan obesitas secara signifikan menurut WHO 2016. Terjadi kenaikan prevalensi yang hampir setara pada anak laki-laki dan perempuan. Pada 19\% anak laki-laki dan $18 \%$ anak perempuan kelebihan berat badan pada tahun 2016. Sementara untuk obesitas lebih besar untuk anak laki-laki di banding anak perempuan, dengan $8 \%$ anak laki-laki dan $6 \%$ anak perempuan mengalamai obesitas pada tahun 2016 [3]. Berdasarkan hasil Riskesdas 2018, didapatkan prevalensi obesitas pada remaja laki-laki lebih besar 5,3\% dibandingkan dengan prevalensi obesitas perempuan sebesar 4,3\%. Prevalensi gemuk remaja usia 16-18 tahun di Indonesia adalah $13,5 \%$ yang terdiri dari 9,5\% gemuk dan $4,0 \%$ sangat gemuk [4]. Masalah obesitas yang terjadi pada anakanak sampai dewasa disebabkan oleh kelebihan gizi. Kebiasaan mengonsumsi fast food diyakini sebagai masalah obesitas [5]. Penelitian Tri Handari dan Loka membuktikan adanya hubungan antara meningkatnya konsumsi fast food dengan status gizi lebih [6].

Makan berlebihan yang terjadi pada orang-orang tertentu biasanya terjadi sebagai tanda dari perasaan stres dan depresi. Bila dibiarkan akan berisiko terjadinya obesitas dan obesitas juga akan mempengaruhi faktor kejiwaan seorang anak karena kurang rasa percaya diri [7]. Penelitian Angraini melaporkan bahwa depresi berhubungan dengan status gizi [8]. Saat ini stres merupakan suatu atribut kehidupan modern karena stres merupakan hal yang tidak bisa terelakkan. Stres bisa terjadi dilingkungan mana saja termasuk lingkungan sekolah, kerja dan keluarga. Siapapun termasuk anak-anak, remaja, dewasa dan usia lanjut bisa mengalami stres [9].

Penelitian Haryono et al., menyatakan bahwa usia 12-15 tahun dihasilkan $62,9 \%$ remaja mempunyai gangguan tidur. Gangguan tidur sendiri mengakibatkan gangguan zat gizi karena berhubung dengan fungsi endokrin, traktus gastrointestinal dan fungsi sirkadian [10]. Di seluruh dunia berdasarkan laporan terjadi peningkatan prevalensi obesitas dan ditemukan penurunan waktu tidur dari tahun ke tahun yang signifikan [11]. Westerlund et al., dan Bel et al., menyatakan tidur yang kurang dapat berhubungan dengan terjadinya peningkatan asupan energi karena banyak mengonsumsi makanan yang mengandung energi tinggi $[12,13]$. Anak remaja yang kurang tidur cenderung memiliki kebiasaan mengonsumsi snack yang mengandung tinggi lemak dan karbohidrat [14]. Berdasarkan uraian di atas konsumsi makanan cepat saji, tingkat stres dan kualitas tidur merupakan faktor yang dapat mempengaruhi status gizi pada remaja. Tujuan dari penelitian ini untuk mengetahui hubungan konsumsi makanan cepat saji, tingkat stres dan kualitas tidur terhadap status gizi pada remaja putra SMA DKI Jakarta.

\section{METODE PENELITIAN Rancangan/Desain Penelitian}

Penelitian ini menggunakan desain cross sectional. Variabel independen yaitu frekuensi konsumsi makanan cepat saji, tingkat stres dan kualitas tidur, sedangkan variabel dependen utama ialah status gizi. 


\section{Sumber Data}

Data primer penelitian didapatkan dengan melakukan penilaian konsumsi makanan cepat saji dengan kuesioner FFQ, penilaian tingkat stres dengan kuesioner ISMA (International Stress Management Association), penilaian kualitas tidur dengan kuesioner PSQI (Pittburgh Sleep Quality Index) dan pengukuran antropometri secara langsung dengan melibatkan personil terlatih. Data lainnya terkait usia dikumpulkan dengan kuesioner terstruktur.

\section{Sasaran Penelitian}

Populasi pada penelitian ini ialah siswa-siswi SMA di DKI Jakarta. Penelitian dilakukan pada remaja putra dari 10 SMA di DKI Jakarta. Diambilnya 10 SMA tersebut berdasarkan jumlah populasi siswa terbanyak setiap SMA dan tingginya prevalensi obesitas pada remaja DKI Jakarta. Tempat penelitian sekolah yang dicari dari setiap wilayah di masingmasing bagian Jakarta dan di setiap wilayah diambil 2 sekolah untuk dijadikan sampel pada penelitian. Populasi berjumlah 2500 orang. Penelitian ini adalah salah satu bagian dari penelitian PEANUT (Physical Activity, Nutrition and Obesity Project). Penelitian ini dilakukan pada bulan Juni sampai bulan Agustus tahun 2019. Pemilihan sampel dilakukan dengan stratified random sampling dengan mempertimbangkan kriteria inklusi dan eksklusi. Kriteria inklusi yaitu: (a) peserta terdaftar sebagai siswa pada saat penelitian, (b) peserta dapat berkomunikasi dengan baik, (c) peserta bersedia mengikuti penelitian selama penelitian berlangsung, dan (d) peserta laki-laki berusia 15-18 tahun. Kriteria eksklusi yaitu: (a) peserta yang tidak masuk sekolah pada saat penelitian berlangsung, dan (b) Peserta yang sedang sakit atau tidak bersedia mengikuti penelitian. Perhitungan sampel dengan menggunakan rumus uji beda proporsi
[15]. Didapatkan sampel sebesar 160 orang. Rumus perhitungan uji beda proporsi:

$$
\mathrm{N}=\frac{\left\{Z_{1-\alpha / 2} \sqrt{2 \bar{P}(1-\bar{P})}+Z_{1-\beta} \sqrt{\left.P_{1}\left(1-P_{1}\right)+P_{2}\left[1-P_{2}\right]\right)}\right\}^{2}}{\left(\mathrm{P}_{1}-\mathrm{P}_{2}\right)^{2}}
$$

Keterangan:

$$
\begin{array}{ll}
\mathrm{N} & =\text { Besarsampel } \\
Z_{1-\alpha / 2} & =\text { Derajat kemaknaan } \alpha \text { pada dua sisi } 5 \% \\
& (1.96) \\
\mathrm{P} & =\text { Proporsi rata-rata }(\mathrm{P} 1+\mathrm{P} 2) / 2 \\
Z_{1-\beta} & =\text { Kekuatan uji } 0.84 \\
\mathrm{P} 1 & =\text { Proporsi kelompok } 1 \\
\mathrm{P} 2 & =\text { Proporsi kelompok } 2
\end{array}
$$

\section{Pengembangan Instrumen dan Teknik Pengumpulan Data}

Penilaian konsumsi makanan cepat saji dilakukan dengan kuesioner FFQ dengan rentang waktu satu bulan terakhir. Bahan makanan yang dimasukkan ke dalam kuesioner FFQ telah disurvey terlebih dahulu pada remaja di SMA DKI Jakarta dan dimasukkan sesuai dengan jenis makanan yang didapatkan pada survey. Pilihan frekuensi yang tersedia ialah lebih dari 3 kali/hari, 1 kali/hari, 3-6 kali/minggu, 1-2 kali/minggu, 2 kali sebulan dan tidak pernah [16]. Tingkat stres diukur dengan kuesioner ISMA (International Stress Management Association) dan kualitas tidur yang diukur dengan kuesioner PSQI (Pittburgh Sleep Quality Index) yang sudah diuji coba setelah diterjemahkan. Pengukuran antropometri meliputi berat badan dan tinggi badan. Diukur menggunakan timbangan badan dan microtoise. Status gizi siswa remaja putra kemudian dihitung dengan software WHO Antroplus untuk indeks IMT/U [17].

\section{Teknik Analisis Data}

Data konsumsi makanan cepat saji, tingkat stres dan kualitas tidur dianalisis dengan bantuan microsoft excel 2010 dan kemudian data tersebut diekspor ke software SPSS 20 untuk dilakukan analisis lebih lanjut. Untuk 
kategori hasil ukur konsumsi makanan cepat saji yaitu dengan hasil ukur skor $\geq 185$ artinya sering dan nilai skor $<185$ artinya jarang mengonsumsi makanan cepat saji. Penilaian angka 185 didapatkan dari hasil median dari data FFQ yang didapatkan. Untuk hasil skor tingkat stres terbagi menjadi tiga yaitu stres berat $\geq 14$ poin, stres sedang 5-13 poin dan stres ringan $\leq 4$ poin. Untuk hasil skor kualitas tidur terbagi menjadi empat yaitu buruk skor $\geq 15$, kurang baik skor 8 14 , cukup baik skor 6-7 dan baik skor 15.

Data disajikan dalam frekuensi dan persen (n, \%). Uji bivariate dilakukan dengan chi-square. Penelitian ini sudah mendapatkan persetujuan kajian etik dari Fakultas Ilmu-Ilmu Kesehatan, Universitas Esa Unggul dengan No. 0319-19.198 /DPKE-KEP/FINALEA/ UEU/ VII / 2019. Persetujuan penelitian yang lain juga didapatkan dari Dinas Pendidikan Pemerintah Provinsi Daerah Khusus Ibukota Jakarta dan Dinas Penanaman Modal dan Pelayanan Terpadu Satu Pintu (PTSP).

Pemberian kode status gizi diberikan kode yaitu kode 0 adalah kurus, kode 1 adalah normal dan kode 2 adalah gemuk. Tingkat FFQ diberikan kode yaitu kode 1 adalah sering dan kode 2 adalah jarang. Tingkat stres diberikan kode 1 adalah stres berat, kode 2 adalah stres sedang dan kode 3 adalah stres ringan. Tingkat kualitas tidur diberikan kode 1 adalah buruk, kode 2 adalah kurang baik, kode 3 adalah cukup baik dan kode 4 adalah baik.

\section{HASIL PENELITIAN}

Sampel rata-rata berusia 16 tahun yaitu sebanyak 69 orang $(43,1 \%)$. Lebih dari setengah sampel $(60 \%)$ mempunyai status gizi normal, $(31,9 \%)$ status gizi gemuk dan $(8,1 \%)$ status gizi kurus. Dari hasil yang didapatkan untuk konsumsi makanan cepat saji pada remaja putra didapatkan lebih banyak untuk kategori sering $(50,6 \%)$, tingkat stres pada remaja putra didapatkan lebih banyak untuk kategori stres sedang sebanyak $96(60 \%)$ dan kualitas tidur pada remaja putra didapatkan paling banyak kualitas tidur yang kurang baik dan cukup baik sebesar 40\% (Tabel 1). Tabel 2 menyajikan tidak ada hubungan antara konsumsi makanan cepat saji dan kualitas tidur dengan status gizi pada remaja putra SMA DKI Jakarta. Sedangkan terdapat hubungan tingkat stres dengan status gizi pada remaja putra SMA DKI Jakarta.

\section{PEMBAHASAN \\ Hubungan Konsumsi Makanan Cepat Saji Terhadap Status Gizi Pada Remaja Putra}

Makanan cepat saji merupakan makanan yang gampang dikemas, disajikan, praktis dan dapat diolah dengan cara produksi yang sederhana. Biasanya makanan cepat saji diolah pada industri pangan yang menggunakan teknologi tinggi. Makanan cepat saji juga ditambahkan zat aditif agar awet dan memberi rasa pada produk tersebut [18].

Berdasarkan penelitian ini didapatkan konsumsi makanan cepat saji yang paling diminati adalah minuman botol, minuman kemasan, fried chicken, nugget, mie instan dan gorengan yang memiliki kandungan gizi tidak seimbang seperti tinggi gula, lemak, tepung dan garam. Temuan pada penelitian ini menunjukan bahwa tidak ada hubungan konsumsi makanan cepat saji terhadap status gizi remaja putra. Dari hasil penelitian didapatkan bahwa remaja putra yang berstatus gizi gemuk lebih banyak yang jarang konsumsi makanan cepat saji dibandingkan dengan yang sering konsumsi makanan cepat saji, hal tersebut menyatakan bahwa konsumsi makanan cepat saji tidak mempengaruhi status gizi karena banyak faktor yang mempengaruhi status gizi yaitu aktivitas fisik, pendidikan gizi, pengetahuan gizi, ketersedian pangan dan sosial budaya. 
Pada penelitian ini didapatkan bahwa lebih banyak remaja putra yang lebih sering mengonsumsi makanan cepat saji. Hal ini sama dengan penelitian Heidy dan Darvan yang menyatakan laki-laki lebih banyak mengonsumsi makanan cepat saji dibandingkan dengan perempuan [19].

Penelitian ini sama dengan penelitian Kristianti et al., dan Widawati yang menyatakan tidak ada hubungan yang signifikan antara frekuensi makanan cepat saji dengan status gizi seseorang [20,21]. Pada penelitian Nusa dan Adi menyatakan ajakan teman sebaya merupakan faktor yang dapat mempengaruhi remaja dalam menentukan makanan cepat saji dari pada menentukan makanan lainnya. Selain ajakan dari teman sebaya, peran orangtua dapat berhubungan dengan perilaku konsumsi makanan cepat saji [22].

Temuan penelitian ini berbalik terbalik pada penelitian Izhar yang menyatakan terdapat hubungan konsumsi fast food dengan status gizi [23]. Makan yang salah yang merupakan kebiasaaan anak dan remaja adalah kebiasaan mengonsumsi makanan cepat saji yang dapat berakibat meningkatkan obesitas [24]. Penelitian Pratiwi menyatakan bahwa kebiasaan mengonsumsi makanan cepat saji akan mempunyai peluang mengalami hipertensi [25]. Sedangkan penelitian Odegaard et al., di Singapura menyatakan bahwa konsumsi makanan cepat saji yang identik dengan negara barat akan menyebabkan resiko lebih tinggi mengalami diabetes mellitus tipe 2 [26], oleh karena itu menurut penelitian Hasibuan menyatakan sebaiknya fast food jangan terlalu sering dikonsumsi, karena jika terlalu sering dikonsumsi dapat menyebabkan penyakit [27].

Tabel 1. Distibusi Frekuensi Berdasarkan Karakteristik Umur Responden, Status Gizi, Konsumsi Makanan Cepat Saji, Tingkat Stres dan Kualitas Tidur Responden Remaja Putra

\begin{tabular}{|c|c|}
\hline Variabel & $\mathrm{n}(\%)$ \\
\hline \multicolumn{2}{|l|}{ Umur } \\
\hline 15 tahun & $56(35,0 \%)$ \\
\hline 16 tahun & $69(43,1 \%)$ \\
\hline 17 tahun & $32(20,0 \%)$ \\
\hline 18 tahun & $3(1,9 \%)$ \\
\hline \multicolumn{2}{|l|}{ Status Gizi } \\
\hline Kurus & $13(8,1 \%)$ \\
\hline Normal & $96(60,0 \%)$ \\
\hline Gemuk & $51(31,9 \%)$ \\
\hline \multicolumn{2}{|l|}{ Konsumsi Makanan Cepat Saji } \\
\hline Sering & $81(50,6 \%)$ \\
\hline Jarang & $79(49,4 \%)$ \\
\hline \multicolumn{2}{|l|}{ Tingkat Stres } \\
\hline Stres Berat & $64(40,0 \%)$ \\
\hline Stres Sedang & $96(60,0 \%)$ \\
\hline \multicolumn{2}{|l|}{ Kualitas Tidur } \\
\hline Buruk & $1(0,6 \%)$ \\
\hline Kurang Baik & $64(40,0 \%)$ \\
\hline Cukup Baik & $64(40,0 \%)$ \\
\hline Baik & $31(19,4 \%)$ \\
\hline Total & $160(100 \%)$ \\
\hline
\end{tabular}

${ }^{1}$ Semua nilai dinyatakan sebagai $\mathrm{n}(\%)$ 
Tabel 2. Distribusi Hubungan Konsumsi Makanan Cepat Saji, Tingkat Stres dan Kualitas Tidur Terhadap Status Gizi Remaja Putra

\begin{tabular}{|c|c|c|c|c|c|c|c|c|c|}
\hline \multirow{3}{*}{ Variabel } & \multicolumn{6}{|c|}{ Status Gizi } & \multirow{2}{*}{\multicolumn{2}{|c|}{ Total }} & \multirow{3}{*}{$p$-value } \\
\hline & \multicolumn{2}{|c|}{ Kurus } & \multicolumn{2}{|c|}{ Normal } & \multicolumn{2}{|c|}{ Gemuk } & & & \\
\hline & $\mathrm{n}$ & $\%$ & $\mathrm{n}$ & $\%$ & $\mathrm{n}$ & $\%$ & $\mathrm{n}$ & $\%$ & \\
\hline \multicolumn{10}{|c|}{ Konsumsi Makanan Cepat Saji } \\
\hline Sering & 4 & 4,9 & 53 & 65,4 & 24 & 29,6 & 81 & 100 & \multirow[t]{2}{*}{0,210} \\
\hline Jarang & 9 & 11,4 & 43 & 54,4 & 27 & 34,2 & 79 & 100 & \\
\hline \multicolumn{10}{|l|}{ Tingkat Stres } \\
\hline Stres Berat & 4 & 6,2 & 47 & 73,4 & 13 & 20,3 & 64 & 100 & \multirow{2}{*}{0,017} \\
\hline Stres Sedang & 9 & 9,4 & 49 & 51,0 & 38 & 39,6 & 96 & 100 & \\
\hline \multicolumn{10}{|l|}{ Kualitas Tidur } \\
\hline Buruk & 0 & 0,0 & 1 & 100 & 0 & 0,0 & 1 & 100 & \multirow{4}{*}{0,165} \\
\hline Kurang Baik & 7 & 10,9 & 31 & 48,4 & 26 & 40,6 & 64 & 100 & \\
\hline Cukup Baik & 2 & 3,1 & 45 & 70,3 & 17 & 26,6 & 64 & 100 & \\
\hline Baik & 4 & 12,9 & 19 & 61.3 & 8 & 25,8 & 31 & 100 & \\
\hline
\end{tabular}

\section{Hubungan Tingkat Stres terhadap Status Gizi pada Remaja Putra}

Stres adalah tekanan yang dialami seseorang dalam menghadapi tuntutan atau harapan yang tidak sesuai dengan kemampuannya [28]. Stres juga merupakan suatu kondisi dimana seseorang yang dipengaruhi oleh tuntutan fisik dan psikologis [29].

Berdasarkan penelitian ini didapatkan hubungan antara tingkat stres terhadap status gizi remaja putra. Dari hasil penelitian remaja putra lebih banyak melakukan bermain olahraga/games dengan benar-benar berusaha untuk menang dengan siapapun mereka bermain, mendapati diri sendiri memikirkan masalah bahkan ketika seharusnya bersantai, mengalami perubahan suasana hati dan kesulitan membuat keputusan dan konsentrasi. Hal ini dapat menyebabkan suatu tekanan dan pikiran sehingga apabila jika terus berlangsung cukup lama maka akan meningkatkan ketegangan dan tingkat stres di dalam diri sendiri. Remaja lakilaki yang sedang stres biasanya akan melakukan perbuatan yang negatif yaitu seperti konsumsi rokok dan alkohol [30].

Penelitian ini sama dengan penelitian Manginte, Goldschmidt et al., dan Bitty et al. yang menyatakan bahwa terdapat hubungan stres dengan status gizi [31-33]. Adanya stres psikologi dapat mengakibatkan aktivasi kronis pada sistem neuroendokrin. Kortisol dapat merangsang peningkatan deposisi lemak pusat, terjadi penurunan leptin akan memberikan sinyal adipostatik dan terjadi peningkatan ghrelin yang memberikan sinyal oreksigenik, yang akan mengakibatkan peningkatan nafsu makan dan asupan makanan [34].

Menurut Lubis depresi bisa mempengaruhi pola makan dan pola makan bisa mengakibatkan depresi. Gangguan pola makan mempunyai hubungan 2 arah. Orang yang mempunyai depresi memiliki dua kecenderungan yaitu tidak nafsu makan yang menyebabkan lebih kurus atau meningkatnya nafsu makanan pada makanan manis sehingga menjadi lebih gemuk [35]. Pernyataan ini senada 
dengan pendapat Nadaek, keadaan stres pada siswa dapat mengakibatkan perubahan nafsu makan, sehingga siswa yang gemuk dan obesitas akan lebih banyak konsumsi energi, sedangkan siswa yang kurus akan lebih mengurangi konsumsi energi [36]. Temuan penelitian ini berbalik terbalik pada penelitian Nisa dan Fiskasari yang menyatakan tidak terdapat hubungan bermakna antara stres dengan status gizi $[37,38]$.

\section{Hubungan Kualitas Tidur terhadap Status Gizi pada Remaja Putra}

Tidur adalah kebutuhan fisiologis untuk manusia dan suatu keadaan alami karena terjadi perubahan status kesadaran, yang ditandai dengan penurunan kesadaran dan respon. Tidur yang tidak berkualitas akan menurukan konsentrasi belajar, penambahan berat badan dan menyebabkan penyakit degeneratif [39].

Sesorang yang cukup tidur di tentukan dari jumlah waktu tidur dan kedalaman tidur. Kesehatan fisiologis dan psikologis akan menurun jika mengalami kualitas tidur yang buruk. Secara fisiologis kualitas tidur yang buruk akan mengakibatkan turunnya tingkat kesehatan dan meningkatkan lelah bahkan secara psikologis menyebabkan emosional tidak stabil, percaya diri kurang, impulsif yang berlebih dan kecerobohan [40].

Terkait kualitas tidur penelitian ini menunjukan tidak terdapat hubungan antara kualitas tidur dengan status gizi remaja putra. Berdasarkan penelitian diketahui bahwa remaja putra lebih banyak tidur jam 10-11 malam dan mengantuk 1-2 kali dan $\geq 3$ kali dalam seminggu ketika melakukan aktifitas disiang hari. Hal ini dapat menyebabkan kurangnya kesegaran dan kebugaran ketika terbangun karena waktu tidur yang kurang yang dapat mengurangi konsentrasi remaja putra ketika sedang melakukan kegiatan belajar di kelas sehingga dapat menyebabkan belajar menjadi sulit dan tidak efisien. Dari penelitian ini didapatkan bahwa remaja putra yang memiliki status gizi normal lebih banyak yang mempunyai kualitas tidur kurang baik dibandingkan dengan yang mempunyai status gizi gemuk.

Hal ini didukung pada penelitian Saputri yang menyatakan bahwa tidak ada hubungan antara durasi tidur dengan obesitas pada remaja SMPN 2 Klego Boyolali [41]. Hal ini sama dengan penelitian Wulandari et al., yang juga menyatakan bahwa tidak ada hubungan pada durasi tidur dengan kejadian obesitas pada siswa SMA Negeri 4 Kendari [42]. Hal ini dikarenakan durasi tidur adalah faktor tidak langsung status gizi. Untuk faktor langsung status gizi adalah dipengaruhi asupan makan dan infeksi [41]. Penelitian Wulandari et al., menyatakan bahwa masa remaja merupakan masa pubertas sehingga remaja cenderung mempunyai kebisaan begadang, yang mana dilakukan oleh remaja obesitas atau remaja yang tidak mengalami obesitas. Kebiasaan begadang dilakukan dengan macam-macam alasan yaitu mengerjakan tugas, games, membuka media sosial, chatting dan saling berbalas pesan singkat dengan teman bahkan pacar [42].

Sedangkan pada penelitian yang dilakukan oleh Khasan menunjukan bahwa terdapat hubungan yang bermakna antara kualitas tidur dengan status gizi [43]. Beberapa penelitian yang dilakukan cross sectional oleh Lytle et al., dan penelitian longitudinal yang dilakukan oleh Seegers et al., manyatakan terdapat hubungan antara durasi tidur yang kurang dengan obesitas pada remaja $[44,45]$.

Berdasarkan penelitian ini saat pengambilan data ada beberapa responden yang kurang kooperatif yang tidak mendengarkan dengan baik atau mengganggu responden lain pada saat 
pengisian angket. Namun pada saat penelitian berlangsung peneliti dibantu oleh enumerator dari bidang gizi yang selalu mengawasi ketika pengisian angket sehingga dapat meminimalisir responden agar tidak saling mencontek. Berdasarkan penelitian ini perlu adanya edukasi gizi dalam bentuk penyuluhan pada remaja putra yang dapat menambah informasi kesehatan mengenai makanan yang sehat dan bergizi, kualitas tidur yang baik dan cara mengendalikan pikiran agar tidak terjadinya stres yang akan berdampak buruk bagi tubuh serta perlunya kebiasaan membawa bekal ke sekolah yang dapat mengurangi konsumsi makanan cepat saji.

\section{SIMPULAN}

Dari penelitian yang dilakukan didapatkan faktor yang mempengaruhi status gizi pada remaja putra SMA DKI Jakarta yaitu tingkat stres sedangkan faktor konsumsi makanan cepat saji dan kualitas tidur tidak berhubungan dengan status gizi remaja putra SMA DKI Jakarta. Pada penelitian ini didapatkan lebih banyak remaja putra yang sering mengonsumsi makanan cepat saji, lebih banyak remaja putra yang mengalami tingkat stres sedang dan lebih banyak kualitas tidur remaja putra yang mangalami kualitas tidur kurang baik dan cukup baik.

\section{UCAPAN TERIMAKASIH}

Ucapan terima kasih kepada PT. Indofood, Dinas Pendidikan Pemerintah Provinsi Daerah Khusus Ibukota Jakarta dan Dinas Penanaman Modal dan Pelayanan Terpadu Satu Pintu (PTSP).

\section{DAFTAR RUJUKAN}

1. Laus MF, Souza MG, Moreira R de CM, Braga-Costa TM. Body Image Dissatisfaction, Nutritional Status, and Eating Attitudes in Adolescents. Acta Sci Heal Sci. 2013; 35 (2): 243 237.
2. Blashill AJ, Wilhelm S. Boys : Longitudinal Trajectories into Adulthood. 2015; 15 (4): 445-51.

3. WHO. Overweight and Obesity: Prevalence of Obesity among Children and Adolescent. Global Health Observatory (GHO) Data. 2016.

4. Riskerdas. Riset Kementrian Dasar. Laporan Nasional 2018. 2018.

5. Hidayah A. Kesalahan-kesalahan Pola Makan Pemicu Seabrek Penyakit Mematikan. Jogjakarta: Penerbit Buku Biru. 2011; 122-128.

6. Tri Handari SR, Loka T. Hubungan Aktivitas Fisik dan Kebiasaan Konsumsi Fast Food dengan Status Gizi Lebih Remaja SMA Labschool Kebayoran Baru Jakarta Selatan Tahun 2016. J Kedokt dan Kesehat. 2017; 13 (2): 153.

7. Nemiary D, Shim R, Mattox G, Holden K. The Relationship between Obesity and Depression among Adolescents. Psychiatr Ann. 2012; 42 (8): 305-8.

8. Angraini dian isti. Hubungan Depresi dengan Status Gizi. MEDULA. 2014; 2 (2): 39-46.

9. Kuprivanov, Zhdanoy. The Eustress Concept: Problems and Out-looks. World J Med Sci. 2014; 11 (2): 179_ 85.

10. Haryono, Rindiarti, Arianti, Pratiwi, Ushuluddin, Setiawati. Prevalensi Gangguan Tidur pada Remaja Usia 12-15 Tahun di Sekolah Lanjutan Tingkat Pertama. Sari Pediatr. 2009; 11 (3): 149-54.

11. Gradisar M, Gardner G, Dohnt H. Recent Worldwide Sleep Patterns and Problems During Adolescence: A Review and Meta-Analysis of Age, Region, and Sleep. Sleep Med. 2011; 12 (1): 110-8.

12. Westerlund L, Ray C, Roos E. Associations between Sleeping Habits and Food Consumption Patterns among 10-11 Year-Old 
Children in Finland. Br J Nutr. 2009; 102 (10): 1531-7.

13. Bel S, Michels N, De Vriendt $T$, Patterson E, Cuenca-García M, Diethelm K, et al. Association between Self-Reported Sleep Duration and Dietary Quality in European Adolescents. $\mathrm{Br} \mathrm{J}$ Nutr. 2013; 110 (5): 949-59.

14. Weiss A, Xu F, Storfer-isser A, Thomas A, Levers-landis carolyn E, Redline S. The Association of Sleep Duration with Adolescents' Fat and Carbohydrate Consumption. Sleep. 2010; 33 (9): 1201-9.

15. Lemeshow, DW H, K J, SK L. Besar Sampel dalam Penelitian Kesehatan. Pramono D, penerjemah. Yogyakarta: Gadjah Mada University Press; 1997.

16. Sirajuddin, Surmita, Astuti T. Survey Konsumsi Pangan. Edisi 2018. Kementrian Kesehatan Republik Indonesia. 2018; 161-162.

17. Blössner M, Siyam A, Borghi E, Onis $\mathrm{M}$ de, Onyango A, Yang $\mathrm{H}$. WHO AnthroPlus Software. Switzerland: Department of Nutrition for Health and Development, Geneva. 2011.

18. Valoka AD. Dampak Negatif Makanan Cepat Saji terhadap Kesehatan Tubuh Manusia di Kota Bandung melalui Still Life Photography. (Skripsi). Universitas Pasundan, Bandung. 2017.

19. Heidy DS. Hubungan Frekuensi Konsumsi Makanan Cepat Saji dengan Tekanan Darah pada Remaja SMP Permai Penjaringan Jakarta Utara. Mandala Heal A Sci J. 2018; 11 (2): 61-9.

20. Kristianti N, Sarbini D, Mutalazimah. Hubungan Pengetahuan Gizi dan Frekuensi Konsumsi Fast Food dengan Status Gizi Siswa SMA Negeri 4 Surakarta. J Kesehat. 2009; 2 (1): 39-47.

21. Widawati. Gambaran Kebiasaan
Makan dan Status Gizi Remaja di SMAN 1 Kampar Tahun 2017. J Gizi Nutr J [Internet]. 2018; 2 (2013): 146-59. Available from: https://journal.universitaspahlawan.a c.id/index.php/jurnalgizi/article/view $/ 201$

22. Nusa AFA, Adi AC. Hubungan Faktor Perilaku, Frekuensi Konsumsi Fast Food, Diet dan Genetik dengan Tingkat Kelebihan Berat Badan. Media Gizi Indones. 2013; 9 (1): 20 7.

23. Izhar MD. Hubungan antara Konsumsi Junk Food, Aktivitas Fisik dengan Status Gizi Siswa SMA Negeri 1 Jambi. J Formil (Forum Ilmiah) Kesmas Respati. 2020; 5 (1): $1-7$.

24. Rafiony A, Purba MB, Pramantara IDP. Konsumsi Fast Food dan Soft Drink sebagai Faktor Risiko Obesitas pada Remaja. J Gizi Klin Indones. 2015; 11 (4): 170-8.

25. Pratiwi MW. Hubungan Pola Makan Fast Food dengan Kejadian Hipertensi pada Usia Produktif di Dusun Tegal Ngijon Sumber Agung Moyudan Sleman Yogyakarta. (Skripsi). Sekolah Tinggi Ilmu Keperawatan 'Aisyiyah Yogyakarta. 2010.

26. Odegaard AO, Koh WP, Yuan J-M, Gross MD, Pereira MA. WesternStyle Fast Food Intake and Cardiometabolic Risk in an Eastern Country. Circulation. 2012; 126 (2): 182-8.

27. Hasibuan R. Perilaku Makan Siap Saji (Fast Food) dan Kejadian Obesitas Remaja Putri di SMA Negeri 1 Barumun Kecamatan Barumun Kabupaten Padang Lawas. (Skripsi). Fakultas Kesehatan Masyarakat Universitas Sumatera Utara, Medan. 2015.

28. Kholidah EN, Alsa A. Berpikir Positif untuk Menurunkan Stres Psikologis. J Psikol. 2012; 39 (1): 
$67-75$.

29. Kartika CD. Hubungan antara Kecerdasan Emosi dengan Stres Akademik Mahasiswa Fakultas Psikologi Universitas Muhammadiyah Surakarta. (Skripsi). Fakultas Psikologi. Universitas Muhammadiyah Surakarta. 2015.

30. Zimmer-Gembeck MJ, Skinner EA. Adolescents Coping with Stress: Development and Diversity. School Nurse News. 2010; 27 (2): 23-8.

31. Manginte AB. Hubungan antara Stres dengan Status Gizi Mahasiswa Program S1 Keperawatan Semester VIII Stikes Tana Toraja Tahun 2015. J Agrosaint. 2015; VI (3): 182-92.

32. Goldschmidt AB, Wall MM, Loth KA, Neumark-Sztainer D. Risk Factors for Disordered Eating in Overweight Adolescents and Young Adults. J Pediatr Psychol. 2015; 40 (10): 1048-55.

33. Bitty F, Asrifuddin A, Nelwan JE. Stres dengan Status Gizi Remaja di Sekolah Menengah Pertama Negeri 2 Manado. J KESMAS. 2018; 7 (5): 16.

34. Ranabir S, Reetu K. Stress and hormones. Indian $\mathrm{J}$ Endocrinol Metab. 2011; 15 (1): 18-22.

35. Lubis NL. Depresi: Tinjauan Psikologis. Jakarta: Kencana Prenada Media Grup. 2009; 1-36.

36. Nadaek TA. Hubungan Stres Psikososial dengan Konsumsi Makan dan Status Gizi Siswa SMU Methodist-8 Medan. (Skripsi). Departemen Gizi Kesehatan Masyarakat FKM USU, Medan. 2013.

37. Nisa AC. Hubungan Tingkat Stres dengan Konsumsi Makan dan Status Gizi pada Siswa Kelas X di SMA Negeri 1 Teras Boyolali. (Skripsi). Universitas Muhammadiyah Surakarta. 2016.

38. Fiskasari SR. Hubungan Depresi, Ansietas dan Stres dengan Status
Gizi pada Mahasiswa Fakultas Kedokteran Universitas Lampung. (Skripsi). Universitas Lampung. 2019.

39. Sitoayu L, Rahayu P. Hubungan Asupan Vitamin (B6, B12, Asam Folat), Olahraga dan Kualitas Tidur pada Mahasiswa Universitas Esa Unggul Tahun 2016. Media Gizi Mikro Indones. 2019; 11 (1): 73-82.

40. Sulistiyani C. Beberapa Faktor yang Berhubungan dengan Kualitas Tidur pada Mahasiswa Fakultas Kesehatan Masyarakat Universitas Diponegoro Semarang. J Kesehat Mayarakat. 2012; 1 (2): 280-92.

41. Saputri W. Hubungan Aktivitas Fisik dan Durasi Tidur dengan Status Gizi pada Remaja Di SMP N 2 Klego Boyolali. (Skripsi). Sekolah Tinggi Ilmu Kesehatan PKU Muhammadiyah Surakarta. 2018.

42. Wulandari S, Lestari H, Fachlevy AF. Faktor yang Berhubungan dengan Kejadian Obesitas pada Remaja di SMA Negeri 4 Kendari Tahun 2016. J Ilm Mhs Kesehat Masy. 2016; 1 (3): 1-13.

43. Khasan N. Hubungan Kualitas Tidur dengan Status Gizi pada Anak SMA. (Skripsi). Universitas Trisakti. 2017.

44. Lytle LA, Pasch KE, Farbakhsh K. The Relationship between Sleep and Weight in a Sample of Adolescents. Obesity (Silver Spring) [Internet]. 2011; 19 (2): 324-31. Available from:

http://www.ncbi.nlm.nih.gov/pubme d/20948522\%0Ahttp://www.pubmed central.nih.gov/articlerender.fcgi?arti d=PMC3099473

45. Seegers V, Petit D, Falissard B, Vitaro F, Tremblay RE, Montplaisir J, et al. Short Sleep Duration and Body Mass Index: A Prospective Longitudinal Study in Preadolescence. Am J Epidemiol. 2011; 173 (6): 621-9. 